\title{
Keputusan Berlangganan Aplikasi Konferensi Video: Analisis Pengetahuan Konsumen dan Getok Tular Elektronik
}

\author{
Glorius Parulian Yuwono Setra ${ }^{a^{*}}$, Rafika Puspitasari ${ }^{b}$ \\ anstitut Komunikasi dan Bisnis LSPR \\ bInstitut Komunikasi dan Bisnis LSPR \\ *21072140018@lspr.edu
}

\begin{abstract}
The COVID-19 pandemic has minimized face-to-face meetings within the public. The reality shows that video-conference application is the solution so that people can still be connected face-to-face through online video even though they're separated by distance and time. There are actually many video-conference applications on the market. However, Zoom Premium is considered to be popularly used and has become a public conversation since the COVID-19 pandemic. Someone who decides to subscribe to the Zoom Premium application is estimated to be influenced by their knowledge and public reviews that are scattered on social media regarding Zoom Premium. Therefore, this study aims to determine how much influence that product knowledge and electronic word-of-mouth (EWOM) have on the decision to subscribe to the Zoom Premium application. This study applies quantitative approach with online questionnaire being distributed through purposive sampling to one hundred and ten customers of the Zoom Premium application in Indonesia. The method used in this study is multiple regression analysis and utilizes the SPSS 26 application. The result shows that product knowledge and electronic word of mouth simultaneously influence $43.4 \%$ of the decision to subscribe to the Zoom Premium application. Partially, each of them is also influential.
\end{abstract}

Keywords: electronic word of mouth, product knowledge, purchase decision, Zoom Premium application

\section{Pendahuluan}

Masyarakat memiliki kecenderungan untuk selalu mengikuti perkembangan zaman dengan memanfaatkan kemajuan teknologi komunikasi dan media-media baru (new media) masa kini. Istilah mediamorfosis menjelaskan bentuk media yang selalu mengikuti zaman demi menghasilkan fungsi yang terbaik (Sudarsono \& Olivia, 2021). Media saat ini sedang berada pada era digital. Khalin \& Chernova $(2018$, p. 46) mengatakan bahwa perkembangan ekonomi dan kehidupan sosial saat ini sangat bergantung pada fenomena digitalisasi. Digitalisasi tersebut dapat terlihat dalam pola masyarakat yang semakin menyesuaikan persoalan modernitas saat ini (Fauziyah, 2014). Salah satunya adalah perubahan perilaku masyarakat dalam menjalankan konferensi. Banyak aplikasi penyedia layanan komunikasi jarak jauh yang akhirnya digunakan sebagai alternatif tatap muka oleh masyarakat, seperti salah satunya aplikasi konferensi video untuk berkomunikasi secara daring. Survei konsumen yang dilakukan oleh Populix pada Juni 2020 silam menunjukkan adanya peningkatan yang signifikan dalam penggunaan aplikasi konferensi video, yakni sebesar 31,7\% (Populix, 2020). Dengan demikian, hasil ini menjelaskan bahwa terjadi perubahan kebiasaan terhadap penggunaan aplikasi konferensi video yang dimanfaatkan untuk memenuhi kebutuhan dalam berkomunikasi jarak jauh.

Hal lain yang semakin mendukung perubahan pola komunikasi jarak jauh pada masyarakat yang memanfaatkan aplikasi konferensi video adalah pandemi COVID-19. Menurut data Worldometer (2021), Indonesia menempati peringkat 20 besar kasus positif pada tingkat global dan menempati posisi ke-2 pada tingkat Asia, setelah India. Ruang gerak dan pertemuan secara tatap muka yang terbatas mengakibatkan masyarakat sulit berinteraksi secara langsung di tengah pandemi COVID-19. Lantas, pandemi COVID19 menyebabkan komunikasi digital menjadi pilihan favorit bagi mayoritas masyarakat 
karena faktor ubikuitas yang dimilikinya (West \& Turner, 2019, p. 377). Ubikuitas yang ada pada aplikasi konferensi video memudahkan masyarakat untuk dapat bersosialisasi satu sama lain (Tumengkol, 2020). Dengan demikian, penting bagi masyarakat untuk dapat mengetahui aplikasi konferensi video mana yang tepat untuk memenuhi kebutuhannya. Konsumen merupakan stakeholder yang kenyamanannya sangat dipertimbangkan oleh berbagai aplikasi penyedia layanan komunikasi jarak jauh karena tingkat unduhan konsumen menjadi faktor keberhasilan utama. Oleh sebab itu, banyak aplikasi penyedia layanan komunikasi jarak jauh yang berlomba-lomba untuk menawarkan fitur-fitur terbaik demi menarik hati para konsumen.

Aplikasi konferensi video sebenarnya sudah sejak lama digunakan oleh masyarakat, salah satu pelopornya adalah Skype. Aplikasi ini dirilis sejak tahun 2003 dan mencapai seratus juta pengguna pada tahun 2006 (123ish, 2019). Masyarakat pada saat itu memanfaatkan aplikasi konferensi video untuk keperluan relasi antarnegara (Mubtadi, 2011), serta untuk menjalankan kelas perkuliahan jarak jauh (Salsabila, 2013). Namun semenjak pandemi COVID-19 melanda, aplikasi konferensi video telah menjadi bagian hidup masyarakat dan tidak lagi digunakan sebatas kebutuhan dalam bidang profesional saja.

Zoom menjadi salah satu aplikasi penyedia layanan komunikasi jarak jauh berbasis video yang diunduh banyak orang (Baltrusaitis, 2020). Hal ini dibuktikan dari data yang dipaparkan oleh Databoks, di mana aplikasi Zoom telah diunduh sebanyak 681 juta kali pada tahun 2020, sedangkan para kompetitornya dalam ranah aplikasi konferensi video, Google Meet hanya diunduh 331 juta kali, Microsoft Teams hanya diunduh 200 juta kali, dan Cisco Webex Meetings hanya diunduh sebanyak 65 juta kali. Katadata juga lebih lanjut menjelaskan bahwa dengan adanya kebijakan PSBB (Pembatasan Sosial Berskala Besar), kegiatan belajar mengajar (KBM) dan rapat daring memanfaatkan aplikasi Zoom, demi mencegah penularan virus COVID-19 (Annur, 2020).

Tabel 1. Jumlah Unduhan Aplikasi Bisnis pada Tahun 2020

\begin{tabular}{cc}
\hline Aplikasi & Jumlah Unduhan \\
\hline Zoom & 681 juta \\
Google Meet & 331 juta \\
Microsoft Teams & 200 juta \\
WhatsApp Business & 166 juta \\
Adobe Acrobat Reader & 83 juta \\
Cisco Webex Meetings & 65 juta \\
\hline
\end{tabular}

Sumber: Databoks (2020)

Saat pandemi COVID-19, aplikasi Zoom merupakan aplikasi yang paling banyak diunduh untuk keperluan bisnis dan diikuti oleh Google Meet dan Microsoft Teams. Ini mengindikasikan bahwa aplikasi Zoom semakin populer di mata masyarakat global sebagai penyedia layanan konferensi video untuk menunjang aktivitas bisnis. Hal ini membuat peneliti tertarik untuk menelaah aplikasi Zoom pada penelitian ini. Namun, di tengah maraknya penggunaan aplikasi layanan komunikasi jarak jauh, Zoom pernah mengalami pemberitaan mengenai isu keamanan privasi yang dapat menjadi ancaman bagi seluruh pihak yang pernah menggunakan aplikasi Zoom pada kuartal awal 2020. Hal ini mengakibatkan banyaknya para pengguna menjadi khawatir, padahal privasi merupakan unsur penting dalam relasi stakeholders dengan perusahaan (Martin \& Murphy, 2017, p. 140).

Walaupun ada isu terkait soal keamanan, menariknya aplikasi Zoom tetap digunakan oleh masyarakat, bahkan pengguna aplikasi Zoom semakin melonjak naik (Pertiwi, 2020). Aplikasi Zoom dapat digunakan secara gratis, tetapi durasi pertemuan 
dan jumlah peserta dibatasi. Sebagian besar masyarakat yang menggunakan aplikasi Zoom merasa tidak puas dan memutuskan untuk berlangganan aplikasi Zoom versi Premium. Aplikasi Zoom Premium dapat digunakan secara unlimited session, jadi para penggunanya tidak perlu khawatir terhadap waktu yang terbatas. Faktor keamanan yang ditawarkan oleh aplikasi Zoom Premium juga sangat bermanfaat. Pengguna dapat meningkatkan kemananan terhadap data-data penting selama menggunakan Zoom. Dengan demikian, pelanggan tidak perlu khawatir jika ada kebocoran data atau isu keamanan privasi lainnya pada aplikasi Zoom.

Faktor terkait pengetahuan konsumen akan aplikasi Zoom Premium itu sendiri semakin membuat calon konsumen tertarik untuk berlangganan. Pengetahuan produk didefinisikan sebagai seberapa besar dan dalam konsumen menyadari karakteristik produk sebelum membelinya, yang mana biasanya berkaitan dengan atribut, keuntungan, dan nilai kepuasan (Peter \& Olson, 2013, pp. 68-69).

Beberapa penelitian terdahulu mengakui bahwa pengetahuan produk dapat membuahkan hasil berupa keputusan pembelian. Annisa dan Wijaya (2019) menjelaskan bahwa pengetahuan produk memiliki pengaruh terhadap keputusan pembelian obat herbal yang berupa jamu masuk angin kemasan. Rusniati dan Rahmawati (2019) juga menjelaskan bahwa pengetahuan produk memiliki pengaruh terhadap keputusan pembelian green product di Banjarmasin. Maulana et al. (2020) juga menjelaskan bahwa pengetahuan produk memiliki pengaruh terhadap keputusan menggunakan Bank Aceh Syariah KCP Samatiga. Sitompul (2021) menjelaskan bahwa pengetahuan produk memiliki pengaruh terhadap keputusan pembelian produk kosmetik di kota Medan. Selain itu, Rajaguguk et al. (2021) menjelaskan bahwa pengetahuan produk memiliki pengaruh terhadap proses keputusan pembeli di Homesmart Rantau Prapat saat pandemi COVID-19.

Berdasarkan penelitian-penelitian terdahulu di atas, dapat diperkirakan adanya pengaruh yang ditimbulkan oleh pengetahuan produk pada keputusan pembelian. Hal ini karena saat konsumen dihadapkan dengan situasi dan kondisi yang memerlukan aplikasi konferensi video, konsumen akan berusaha untuk mengenali karakter dari setiap aplikasi konferensi video yang ada sebelum akhirnya memutuskan untuk berlangganan. Tujuan konsumen mengetahui karakter dari setiap opsi aplikasi konferensi video adalah agar konsumen dapat menemukan aplikasi mana yang paling sesuai dengan karakter dirinya (kebutuhan). Maka dari itu, peneliti memiliki hipotesis sebagai berikut:

H1: Pengetahuan produk berpengaruh terhadap keputusan pembelian.

Konsumen yang berpengetahuan lebih tinggi, dalam hal ini terkait aplikasi Zoom Premium, akan lebih realistis dalam memilih dan menggunakan aplikasi konferensi video sesuai harapan serta kebutuhannya. Pengetahuan produk merupakan hal yang sangat penting untuk dikomunikasikan secara luas kepada konsumen. Hal ini disebabkan erat kaitannya dengan berhasil atau tidaknya sebuah aktivitas pemasaran. Jika konsumen dapat teredukasi dengan baik mengenai aplikasi Zoom Premium, dapat dikatakan pemasar berhasil memberikan edukasi kepada konsumen, khususnya dalam menunjukkan keunggulan dan keunikan produknya dibanding pesaing.

Faktanya, konsumen sering kali mencari informasi terkait produk yang dibutuhkan. Namun, dari banyaknya pilihan produk yang tersedia, ada peran rekomendasi orang lain yang menjadi bahan pertimbangan tambahan. Saat ini, di tengah situasi pandemi COVID19 tentunya masyarakat mengandalkan pencarian informasi secara daring. Maka tidak heran, banyaknya getok tular elektronik [Electronic Word of Mouth (EWOM)] yang terjadi. Sejak dahulu, promosi antar pribadi telah dilakukan dan dikenal dengan sebutan word of mouth (WOM) atau getok tular dalam Bahasa Indonesia. Namun di era globalisasi, promosi antar pribadi telah memasuki dunia digital yang dapat dilakukan melalui situs 
web hingga media sosial. Realitas ini melahirkan istilah baru yang disebut EWOM. Hal ini disebabkan konsumen menjadikan teknologi internet sebagai alat dalam melakukan pencarian sebuah informasi mengenai suatu perusahaan atau produk (Weitzl, 2017).

EWOM merupakan jenis komunikasi yang berbeda dengan jenis komunikasi lainnya karena kredibilitas sumbernya sangat tinggi. Hal ini dipertegas oleh Guastella (2017) yang menyatakan bahwa seorang komunikan akan melihat sumber yang jauh lebih meyakinkan sebagai orang yang menyampaikan informasi. Mayoritas masyarakat akan berbagi informasi dengan siapa saja karena siapa pun dapat membaca dan melihat informasi yang beredar di media daring, seperti media sosial serta media yang telah terdigitalisasi lainnya.

Ismagilova, et al. (2017) menyebutkan bahwa getok tular elektronik adalah komunikasi lisan yang dilakukan antar individu melalui teknologi berbasis internet yang berisikan informasi mengenai merek, produk, dan jasa yang ditujukan kepada konsumen lainnya. Informasi terkait aplikasi Zoom Premium dapat ditemukan dari ulasan atau rekomendasi daring yang berasal dari orang yang pernah menggunakan aplikasi Zoom Premium. Menurut Ismagilova et al. (2017, p. 75), ada tiga dimensi yang memengaruhi EWOM. Pertama, kualitas. EWOM mengarah pada kekuatan persuasif dari ulasan yang disematkan dalam pesan yang bersifat informatif. Kualitas ini dilandasi beberapa kriteria atau persyaratan yang memenuhi kebutuhan komunikan. Oleh sebab itu, kualitas EWOM terkait aplikasi Zoom Premium menjadi pacuan seseorang untuk melakukan tahap selanjutnya setelah mencari informasi yang dibutuhkan.

Kedua, kuantitas, yang berhubungan dengan angka dan jumlah. Popularitas aplikasi Zoom Premium disebabkan pada tingginya kuantitas penyebaran informasi melalui EWOM. Dengan kata lain, semakin banyak ulasan, maka semakin menunjukkan eksistensi dan kepentingan aplikasi Zoom Premium.

Ketiga, keahlian. Ini mengacu pada pengalaman, pengetahuan, dan keterampilan yang dimiliki oleh komunikator yang pernah menggunakan aplikasi Zoom Premium. Komunikator yang ahli dan kredibel pada produk tertentu diperlukan untuk menyampaikan pesan melalui EWOM agar komunikan puas dengan informasi aplikasi Zoom Premium yang diberikan oleh komunikator.

Beberapa penelitian terdahulu juga mengakui bahwa EWOM dapat membuahkan hasil berupa keputusan pembelian. Sari et al. (2017) menjelaskan bahwa EWOM membawa pengaruh pada keputusan pembelian konsumen bukalapak.com. Sindunata \& Wahyudi (2018) juga menjelaskan bahwa getok tular elektronik membawa pengaruh pada keputusan pembelian di agoda.com. Akbar \& Sunarti (2018) yang menjelaskan bahwa EWOM membawa pengaruh pada keputusan pembelian konsumen Sushi Tei Kelapa Gading. Sudarita (2020) juga menjelaskan bahwa EWOM membawa pengaruh pada keputusan pembelian produk Jelita Cosmetic. Selain itu, Rupayana et al. (2021) menjelaskan bahwa EWOM membawa pengaruh pada keputusan pembelian ponsel cerdas merek Oppo di Denpasar.

Berdasarkan penelitian-penelitian tersebut, dapat diperkirakan terdapat pengaruh yang ditimbulkan oleh EWOM terhadap keputusan pembelian. Hal ini karena ketika konsumen memerlukan aplikasi berlangganan konferensi video, konsumen akan mencari ulasan maupun rekomendasi dari orang lain. Ulasan maupun rekomendasi dapat calon konsumen Zoom Premium temukan secara daring, seperti di media sosial ataupun situs web. Keputusan konsumen dalam berlangganan aplikasi Zoom Premium pun semakin diperkuat dengan ulasan maupun rekomendasi daring ini. Maka dari itu, peneliti memiliki hipotesis sebagai berikut:

H2: Getok tular elektronik (EWOM) berpengaruh terhadap keputusan pembelian. 
H3: Pengetahuan produk dan getok tular elektronik (EWOM) secara simultan berpengaruh terhadap keputusan pembelian.

Perilaku konsumen merupakan sebuah kajian mengenai individu, kelompok, dan organisasi dalam memilih, membeli, menggunakan dan membuang barang, jasa, ide atau pengalaman untuk memenuhi keinginan dan kebutuhannya (Kotler \& Armstrong, 2015, p. 166). Pengambilan keputusan hadir sebagai sebuah penyelesaian masalah agar tujuan konsumen dapat diraih, dalam hal ini adalah produk konferensi video. Keputusan pembelian merupakan suatu proses pengambilan keputusan oleh konsumen baik individu maupun kelompok dalam barang ataupun jasa untuk memenuhi kebutuhannya.

Menurut Kotler \& Keller (2013, pp. 184-191) terdapat lima tahap dalam proses keputusan pembelian. Pertama, pengenalan masalah. Proses pembelian terjadi saat pembeli mulai menyadari suatu kebutuhan atau masalah yang dipicu oleh rangsangan internal atau eksternal yang menimbulkan rasa kebutuhannya. Misalnya, keinginan untuk berinteraksi secara daring terjadi karena adanya rangsangan internal, sedangkan pengaruh dari rekomendasi orang yang pernah menggunakan aplikasi Zoom Premium merupakan contoh rangsangan eksternal.

Kedua, pencarian informasi. Konsumen mencari dan mengumpulkan informasi yang dibutuhkan terkait aplikasi Zoom Premium. Ketika melakukan pengumpulan informasi, konsumen biasanya akan mempelajari opsi merek yang ada. Semakin banyak informasi yang dimiliki oleh konsumen, maka pengetahuan konsumen terhadap merek akan meningkat.

Ketiga, evaluasi alternatif. Konsumen akan mengevaluasi opsi merek aplikasi konferensi video yang ada. Proses pengevaluasian terjadi berdasarkan pengalaman dan pemahaman konsumen. Hal-hal ini akan memosisikan konsumen pada sikap suka atau tidak suka terhadap suatu objek atau produk.

Keempat, keputusan pembelian. Konsumen pada umumnya akan memutuskan untuk menggunakan aplikasi konferensi video mana yang paling disukai. Selain itu, aplikasi tersebut harus sesuai dengan kebutuhannya. Pembelian terjadi karena berbagai faktor, seperti harga, kualitas, dan manfaat.

Kelima, perilaku pascapembelian. Setelah melakukan pembelian, konsumen akan memiliki pengalaman dengan produk. Pengalaman dapat bersifat buruk ataupun baik sesuai dengan pengalaman dalam menggunakan aplikasi Zoom Premium. Apabila pengalaman yang didapatkan buruk, konsumen cenderung tidak akan membeli kembali dan tidak merekomendasikan merek tersebut. Sebaliknya apabila pengalaman yang didapatkan baik, konsumen cenderung akan membeli kembali dan merekomendasikan merek tersebut.

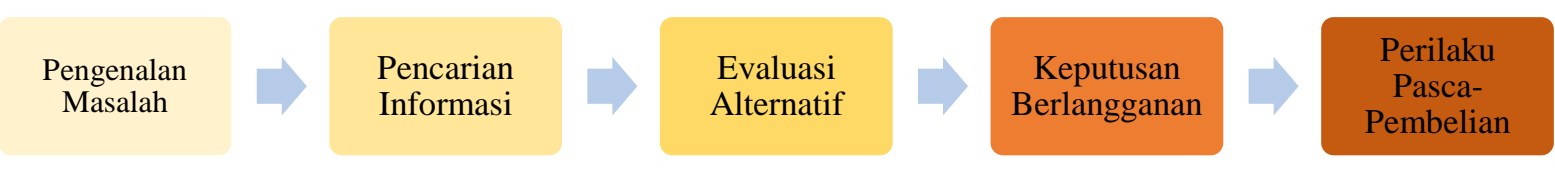

Gambar 1. Proses Keputusan Pembelian

Sumber: Kotler \& Keller (2013, p. 185)

Berdasarkan latar belakang masalah di atas peneliti akan menelaah berapa besar pengaruh pengetahuan produk dan EWOM terhadap keputusan berlangganan aplikasi Zoom Premium. Penelitian ini secara teoretis dapat bermanfaat untuk melengkapi celah penelitian dengan fokus pengetahuan produk dan EWOM pada aplikasi berlangganan. Penelitian ini secara praktis berguna sebagai sumber acuan bagi penelitian selanjutnya yang mengaplikasikan konsep sejenis. 


\section{Metode Penelitian}

Penelitian ini mengaplikasikan paradigma positivistik karena bertujuan mengukur suatu keadaan kausalitas, yaitu seberapa besar pengetahuan produk dan EWOM berpengaruh pada keputusan berlangganan aplikasi Zoom Premium (lihat Gambar 2). Neuman (2014, p. 96) menjelaskan bahwa paradigma positivistik cocok pada penelitian yang berpusat kebenaran absolut dan bermanfaat dalam kasus sebab-akibat. Kebenaran absolut yang dimaksud adalah peneliti tidak melakukan spekulasi, melainkan semua didasarkan atas hasil data yang didapatkan dari responden.

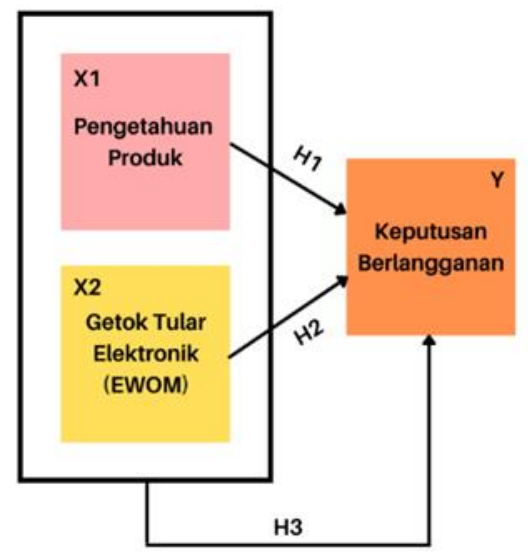

Gambar 2. Model Penelitian

Sumber: Diolah dengan merujuk pada Nepomuceno et al. (2013); Evgeniy et al. (2019); Purnama et al. (2019)

Pendekatan kuantitatif digunakan pada penelitian ini karena peneliti sedang memeriksa teori-teori tertentu dalam relasi antarvariabel (Bryman, 2012, p. 715). Pendekatan kuantitatif juga dipilih karena sifat objektif, deduktif, dan numerik yang dikandung oleh penelitian ini. Instrumen penelitian berupa angket daring yang digunakan untuk mengukur variabel-variabel yang ada agar dapat dianalisis berdasarkan kaidah statistika berupa regresi berganda. Angket daring bersifat self-reported dalam format Google Form, disebarkan kepada 110 pengguna Zoom Premium di Indonesia dengan prinsip purposive sampling.

Data jumlah pengguna Zoom Premium di Indonesia bersifat konfidensial dan tidak dipublikasikan kepada masyarakat. Tidak ada kerangka populasi pasti berapa jumlah pengguna Zoom yang dapat diambil. Keadaan ini mengindikasikan bahwa jumlah populasi penelitian tidak dapat diidentifikasi. Dengan demikian, data ditarik dengan cara purposive sampling. Purposive sampling merupakan teknik penarikan yang membuat peneliti mengambil partisipan atau sampel secara strategis dan relevan sesuai dengan kebutuhan yang diperlukan (Bryman, 2012, p. 714). Kriteria responden pada penelitian ini adalah mereka yang sedang berlangganan aplikasi Zoom Premium. Sifat objektif pada penelitian ini terbukti dengan peneliti hanya akan menjelaskan dari apa yang ditemukan di lapangan (responden) dan mengolahnya secara statistika, tanpa ada unsur opini pribadi.

Populasi pelanggan Zoom Premium di Indonesia saat ini bersifat fluktuatif. Oleh karena itu, peneliti menggunakan rumus penarikan sampel Dattalo (2018, p. 181) yang menyatakan bahwa seyogianya jumlah sampel $(\mathrm{N})$ pada penelitian regresi menjalankan ekuasi: $\mathrm{N}>104+\mathrm{m}$, di mana $\mathrm{m}$ adalah banyaknya variabel independen pada penelitian. Penelitian ini memiliki dua variabel independen, maka sampel yang ditarik perlu lebih dari 106 responden. Peneliti mengumpulkan 110 jawaban responden dan jumlah 
tersebut sudah memenuhi syarat penarikan sampel Dattalo. Seratus sepuluh jawaban ini didapatkan dari hasil menyebarkan angket daring pada tanggal 7 Mei 2021 sampai dengan 21 Mei 2021. Peneliti memanfaatkan media sosial Instagram, WhatsApp, dan Twitter untuk mencari responden-responden tersebut.

Pertanyaan-pertanyaan terkait ketiga variabel pada penelitian ini dinilai dengan skala Likert. Skala Likert digunakan karena peneliti ingin menelaah sikap responden dan cocok digunakan pada tipe angket tertutup (Neuman, 2014, p. 223). Tipe angket tertutup berarti opsi jawaban disediakan oleh peneliti. Indikator-indikator yang digunakan pada penelitian ini dapat dilihat pada Tabel 2. Selain itu, angket penelitian ini juga mengandung lembar kesediaan dan pertanyaan demografi. Uji validitas pada penelitian ini menggunakan analisis faktor. Validitas dapat dibuktikan dengan nilai Keiser Meyer Olkin yang harus lebih besar dari 0,5. Sementara itu, apabila Cronbach's Alpha pada tiap variabel bernilai >0,60, instrumen tersebut dapat dikatakan reliabel (Bryman, 2012, p. 170). Normalitas residual, multikolinearitas, dan heteroskedastisitas digunakan sebagai uji asumsi klasik pada penelitian ini.

Tabel 2. Operasionalisasi Variabel




106 Expose: Jurnal Ilmu Komunikasi, Vol. 4(2), November 2021



Sumber: Diolah dengan merujuk pada Nepomuceno et al. (2013); Evgeniy et al. (2019);

Purnama et al. (2019)

\section{Hasil dan Pembahasan}

Angket daring dalam format Google Form telah disebarkan oleh peneliti kepada 110 pelanggan aplikasi Zoom Premium di Indonesia. Seratus sepuluh jawaban tersebut menghimpun demografi responden terkait gender biologis, usia, pekerjaan, dan kota tinggal. Selain itu, peneliti juga menanyakan intensitas responden dalam menggunakan aplikasi Zoom Premium setiap minggunya, motivasi apa yang mendorong responden menggunakan aplikasi Zoom, serta media sosial yang paling sering digunakan responden untuk bertukar informasi ataupun rekomendasi.

Tabel 3. Operasionalisasi Variabel

\begin{tabular}{|c|c|c|c|}
\hline \multicolumn{2}{|c|}{ Demografi Responden } & \multirow{2}{*}{$\frac{\text { Jumlah }}{72}$} & \multirow{2}{*}{$\begin{array}{c}\text { Persen (\%) } \\
65,5\end{array}$} \\
\hline Gender Biologis & Perempuan & & \\
\hline & Laki-laki & 38 & 34,5 \\
\hline \multirow[t]{3}{*}{ Usia } & $<21$ tahun & 16 & 14,5 \\
\hline & $21-30$ tahun & 72 & 65,5 \\
\hline & $>30$ tahun & 22 & 20 \\
\hline \multirow[t]{5}{*}{ Pekerjaan } & Pegawai Swasta & 37 & 33,6 \\
\hline & Pelajar/Mahasiswa & 40 & 36,4 \\
\hline & PNS/BUMN & 24 & 21,8 \\
\hline & Wirausaha & 2 & 1,8 \\
\hline & Pekerjaan Lain & 7 & 6,4 \\
\hline \multirow[t]{2}{*}{ Kota Tinggal } & Jabodetabek & 69 & 62,7 \\
\hline & Luar Jabodetabek & 41 & 37,3 \\
\hline \multirow{4}{*}{ Intensitas Penggunaan Zoom Premium Tiap Minggu } & 1-2 kali dalam seminggu & 38 & 34,5 \\
\hline & 3-4 kali dalam seminggu & 29 & 26,4 \\
\hline & 5-6 kali dalam seminggu & 27 & 24,6 \\
\hline & Setiap hari & 16 & 14,5 \\
\hline \multirow[t]{3}{*}{ Motivasi Penggunaan Zoom Premium } & Motif Pendidikan & \multirow{3}{*}{\multicolumn{2}{|c|}{$\begin{array}{l}\text { Diakui } 60 \text { responden } \\
\text { Diakui } 61 \text { responden } \\
\text { Diakui } 16 \text { responden }\end{array}$}} \\
\hline & Motif Pekerjaan & & \\
\hline & Motif Keagamaan & & \\
\hline \multirow[t]{7}{*}{ Media Sosial untuk Bertukar Rekomendasi } & Instagram & 56 & 50,9 \\
\hline & Twitter & 7 & 6,4 \\
\hline & TikTok & 8 & 7,3 \\
\hline & Facebook & 3 & 2,7 \\
\hline & YouTube & 8 & 7,3 \\
\hline & Line & 10 & 9 \\
\hline & WhatsApp & 18 & 16,4 \\
\hline
\end{tabular}


Responden pada penelitian ini didominasi oleh perempuan (62,5\%), rentang usia 21-30 tahun (65,5\%), dan tinggal di kawasan Jabodetabek (62,7\%). Mayoritas responden merupakan pelajar atau mahasiswa $(36,4 \%)$, lalu diikuti dengan pegawai swasta $(33,6 \%)$. Peneliti menemukan bahwa rata-rata responden menggunakan aplikasi Zoom Premium sebanyak 1-2 kali setiap minggunya $(26,4 \%)$ dengan dorongan utama dari faktor pekerjaan. Responden pada penelitian ini juga terlihat paling sering menggunakan media sosial Instagram sebagai wadah bertukar rekomendasi (50,9\%), lalu disusul dengan media sosial WhatsApp $(16,4 \%)$.

Tabel 4. Hasil Uji Validitas dan Reliabilitas

\begin{tabular}{ccc}
\hline Variabel & KMO & $\boldsymbol{\alpha}$ \\
\hline Pengetahuan Produk & 0,860 & 0,826 \\
Getok Tular Elektronik & 0,818 & 0,891 \\
Keputusan Pembelian & 0,882 & 0,907 \\
\hline
\end{tabular}

Sumber: Olahan peneliti (2021)

Data keluaran SPSS menunjukkan bahwa semua butir pertanyaan terkait variabel pengetahuan produk terbilang valid. Hal ini ditunjukkan dengan seluruh nilai Keiser Meyer Olkin lebih besar dari 0,7. Instrumen pada penelitian ini mengindikasikan kecermatan dan ketepatan dalam melakukan fungsi ukurnya pada seluruh variabel pada penelitian ini. Skala pada variabel pengetahuan produk terbilang reliabel. Hal ini ditunjukkan dengan nilai Cronbach's Alpha pada variabel pengetahuan produk bersifat lebih besar dari 0,6. Begitu pula pada variabel getok tular elektronik dan variabel keputusan pembelian, terlihat adanya reliabilitas. Instrumen pengukur pada penelitian ini menghasilkan sifat konsisten.

Tabel 5. Hasil Uji Asumsi Klasik

\begin{tabular}{cc}
\hline Uji Asumsi Klasik & Besaran Hasil \\
\hline Asymp. Sig. pada uji one-sample kolmogorov-smirnov & 0,200 \\
VIF pada variabel pengetahuan produk & 1,406 \\
VIF pada variabel getok tular elektronik & 1,406 \\
Sig. pada Spearman's rho variabel pengetahuan produk & 0,165 \\
Sig. pada Spearman's rho variabel getok tular elektronik & 0,251 \\
\hline
\end{tabular}

Sumber: Olahan peneliti (2021)

Data pada penelitian ini juga melewati uji asumsi klasik. Hasil uji one-sample kolmogorov-smirnov menunjukkan bahwa data terdistribusi secara normal. Hal ini dibuktikan dengan nilai Asymp. Sig. yang lebih besar dari 0,05. Hasil uji Variance Inflation Factor (VIF) menunjukkan bahwa tidak ditemukan korelasi antara variabel dependen dan variabel independen. Hal ini dibuktikan dengan nilai VIF pada variabel pengetahuan produk maupun variabel getok tular elektronik yang lebih kecil dari 10. Hasil spearman rank menunjukkan bahwa model regresi dapat digunakan karena tidak adanya pelanggaran asumsi. Hal ini dibuktikan dengan nilai sig. pada Spearman's rho variabel pengetahuan produk maupun variabel getok tular elektronik yang lebih besar dari 0,05.

Variabel pengetahuan produk secara parsial terlihat memengaruhi variabel keputusan pembelian. Hal ini dibuktikan dari hasil uji T, di mana nilai sig. variabel pengetahuan produk $(0,000)$ terbilang lebih kecil dari 0,05. Penelitian ini sejalan dengan hasil temuan para peneliti terdahulu, yakni Annisa dan Wijaya (2019), Rusniati dan Rahmawati (2019), Maulana et al. (2020), Sitompul (2021), dan yang menjelaskan 
adanya pengaruh pengetahuan produk pada keputusan pembelian.

Tabel 6. Coefficients Keluaran SPSS

\begin{tabular}{|c|c|c|c|c|c|c|}
\hline \multicolumn{7}{|c|}{ Coefficients $^{\mathrm{a}}$} \\
\hline & & \multicolumn{2}{|c|}{ Unstandardized Coefficients } & $\begin{array}{c}\text { Standardized } \\
\text { Coefficients }\end{array}$ & & \\
\hline Model & & B & Std. Error & Beta & $\mathrm{t}$ & Sig. \\
\hline \multirow[t]{5}{*}{1} & (Constant) & 15,406 & 2,664 & & 5,782 & 0,000 \\
\hline & Pengetahuan & 0,279 & 0,057 & 0,418 & 4,896 & 0,000 \\
\hline & Produk (X1) & & & & & \\
\hline & Getok Tular & 0,389 & 0,097 & 0,341 & 3,993 & 0,000 \\
\hline & Elektronik (X2) & & & & & \\
\hline a. Depende & able: Keputusan & pelian (Y) & & & & \\
\hline
\end{tabular}

Sumber: Olahan peneliti (2021)

Calon konsumen sebelum menetapkan pilihannya untuk berlangganan suatu aplikasi konferensi video pasti akan mencari tahu banyak informasi. Informasi tersebut dapat berkaitan dengan atribut, keuntungan, maupun nilai kepuasan yang disediakan dari setiap aplikasi konferensi video yang ada. Atribut berupa fitur-fitur yang dimiliki oleh Zoom Premium dibandingkan Zoom versi standar ataupun para kompetitornya disimpan dalam benak konsumen. Konsumen dapat merasakan fitur sesi tanpa batas ketika menggunakan Zoom Premium, fitur breakout room, hingga fitur jajak pendapat.

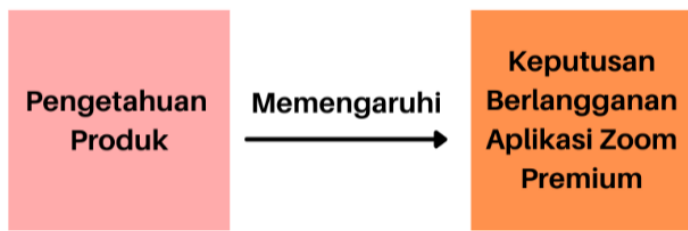

Gambar 3. Ilustrasi Hasil Temuan Variabel X1 terhadap Y Sumber: Olahan Peneliti (2021)

Selain itu, variabel getok tular elektronik secara parsial juga terlihat memengaruhi variabel keputusan pembelian. Hal ini dibuktikan dari hasil uji $\mathrm{T}$, di mana nilai sig. variabel getok tular elektronik $(0,000)$ terbilang lebih kecil dari 0,05 . Penelitian ini sejalan dengan hasil temuan para peneliti terdahulu, yakni Sari et al. (2017), Sindunata dan Wahyudi (2018), Akbar \& Sunarti (2018), Sudarita (2020), dan Rupayana et al. (2021) yang menjelaskan adanya pengaruh getok tular elektronik pada keputusan pembelian.

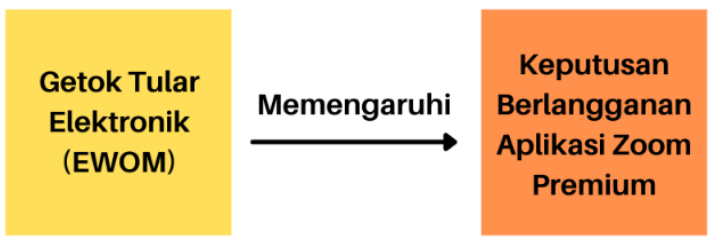

Gambar 4. Ilustrasi Hasil Temuan Variabel X2 terhadap Y Sumber: Olahan Peneliti

Ketika calon konsumen berusaha mengumpulkan informasi demi mendukung pengetahuannya akan sebuah produk, calon konsumen akan mencari ulasan ataupun testimoni sebelum mengambil keputusan pembelian (Sriyanto \& Kuncoro, 2019). Calon konsumen juga sebenarnya tidak sembarang dalam mencari ulasan atau testimoni, karena calon konsumen pastinya akan lebih percaya terhadap apa yang keluar dari mulut konsumen yang pernah menggunakan aplikasi Zoom Premium sebelumnya. Ulasan ataupun testimoni biasanya diungkapkan dalam bentuk pernyataan oleh seseorang 
melalui media sosial yang terlebih dahulu memiliki pengalaman (Utama \& Rosalina, 2016). Para pelanggan yang telah merasakan manfaat dari menggunakan aplikasi Zoom Premium akan berbagi pengalamannya kepada orang lain.

Tabel 7. Model Summary Keluaran SPSS

\begin{tabular}{ccccc}
\hline \multicolumn{5}{c}{ Model Summary } \\
\hline Model & $\mathrm{R}$ & $R$ Square & Adjusted $R$ Square & Std. Error of the Estimate \\
\hline 1 & 0,667 a & 0,444 & 0,434 & 5,613 \\
a. Predictors: (Constant), Getok Tular Elektronik (X2), Pengetahuan Produk (X1) & \\
b. Dependent Variable: Keputusan Pembelian (Y) & & \\
\hline
\end{tabular}
Sumber: Olahan peneliti (2021)

Tabel 8. ANOVA Keluaran SPSS

\begin{tabular}{ccccccc}
\hline \multicolumn{7}{c}{ ANOVA $^{\mathrm{a}}$} \\
\hline Model & \multicolumn{1}{c}{ Sum of Squares } & $\mathrm{df}$ & Mean Square & $\mathrm{F}$ & Sig \\
\hline 1 & Regression & 2697,812 & 2 & 1348,906 & 42,807 & $0,000^{\mathrm{b}}$ \\
& Residual & 3371,679 & & 107 & 31,511 & \\
& Total & 6069,491 & & 109 & &
\end{tabular}

a. Dependent Variable: Keputusan Pembelian (Y)

b. Predictors: (Constant), Getok Tular Elektronik (X2), Pengetahuan Produk (X1) Sumber: Olahan peneliti (2021)

Peneliti kemudian menemukan adanya pengaruh secara simultan dari variabel pengetahuan produk dan variabel getok tular elektronik terhadap variabel keputusan pembelian. Hal ini dibuktikan dari hasil uji F, di mana nilai sig. pada tabel ANOVA $(0,000)$ terbilang lebih kecil dari 0,05. Nilai Adjusted $R^{2}(0,434)$ pada tabel Model Summary, menjelaskan bahwa 43,4\% variasi pada keputusan berlangganan aplikasi konferensi Zoom, dipengaruhi oleh pengetahuan produk dan getok tular elektronik secara serentak (simultan). Persentase sebesar 56,6 berasal dari kontribusi variabel-variabel lain yang tidak ditelaah pada penelitian ini.

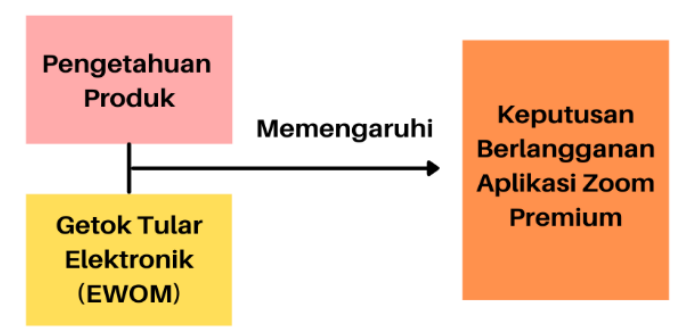

\section{Gambar 5. Ilustrasi Hasil Temuan Variabel X1 dan X2 terhadap Y Sumber: Olahan Peneliti (2021)}

Zoom sudah berdiri sejak tahun 2011, tetapi secara umum menjadi tren baru bagi masyarakat Indonesia semenjak pandemi COVID-19 melanda. Masyarakat mau tak mau didorong untuk beradaptasi dan semakin mengetahui fungsi dari Zoom sebagai aplikasi konferensi video. Hal ini diakui oleh para responden bahwa mereka sebelumnya tidak memiliki banyak pengalaman dengan aplikasi Zoom $(M: 6,29)$. Walaupun tidak memiliki keterlibatan sebelumnya, semakin banyak responden yang memasukkan aplikasi Zoom ke dalam bagian kehidupannya. Kemungkinan besar responden telah melewati proses mencari tahu dan mempelajari dari dasar terkait karakteristik dan fungsional dari aplikasi Zoom. Maka dari itu, tidak heran bahwa tingkat pengetahuan mereka tergolong cukup kuat pada saat ini $(M:$ 6,02). Lantas, dari mana para pengguna Zoom Premium ini mendapatkan pengetahuan produknya? Salah satunya, sudah pasti, berasal dari getok tular elektronik. Responden mengakui bahwa getok tular elektronik yang tersebar 
membicarakan tentang Zoom Premium bersifat jelas dan mudah dimengerti $(M: 5,24)$. Setidaknya, sifat jelas dan mudah dipahami dari getok tular elektronik ini dapat membantu calon pengguna semakin baik dan semakin cepat mempelajari Zoom Premium.

Lalu, ketika calon pengguna menemukan semakin banyaknya orang di media sosial yang mengulas atau membicarakan tentang Zoom Premium, calon pengguna pastinya akan menganggap Zoom Premium sebagai sesuatu yang sedang hangat. Zoom Premium menjadi sesuatu yang perlu calon pengguna ketahui lebih lanjut. Hal ini sejalan dengan pengakuan para responden bahwa mereka semakin membutuhkan Zoom Premium karena tuntutan situasi di sekitarnya $(M: 4,25)$. Orang akan semakin ingin menggunakan produk atau layanan tertentu ketika ia melihat semakin banyak orang ataupun orang di dalam kelompok sosialnya yang ikut menggunakan. Ini sejalan dengan teori network externalities (Wei \& Lu, 2014).

Teori network externalities menjelaskan bahwa manusia pada dasarnya dipersuasi oleh dua hal: (1) perceived number of peers; dan (2) perceived number of users (Wei \& Lu, 2014). Perhatikan dalam data demografi bahwa banyak kaum pelajar hingga kaum pegawai yang menggunakan Zoom Premium. Beragam motif yang membuat mereka menggunakan Zoom Premium, dua di antaranya adalah pendidikan dan pekerjaan. Kenyataan ini mampu menunjukkan banyaknya peers (orang dalam kelompok sosial) yang menggunakan Zoom Premium dalam dunia pendidikan maupun pekerjaan. Para responden ini pun terpengaruh untuk ikut menggunakan Zoom Premium. Peers mempersepsikan bahwa Zoom Premium adalah hal yang bagus dan patut untuk digunakan untuk membantu kinerjanya; calon pengguna juga ikut mempersepsikan hal yang sama. Dengan demikian, masuk akal untuk mengasumsikan bahwa ketika calon pengguna melihat banyaknya peers yang menggunakan Zoom Premium, calon pengguna juga harus menggunakannya agar dapat berinteraksi lebih mudah dengan kelompok sosialnya (Wei \& Lu, 2014).

Selain peers, orang juga mendapatkan informasi dari pengguna lain dari Zoom Premium tersebut yang tak mesti satu kelompok sosial dengannya (users). Ulasan ataupun testimoni yang calon pelanggan dapatkan secara daring, seperti lewat media sosial, dapat menjadi penentu keputusan berlangganan aplikasi Zoom Premium. Bukti konkretnya dapat terlihat dari persamaan hasil uji regresi berganda, yakni apabila getok tular elektronik berkontribusi sebanyak satu satuan, keputusan untuk berlangganan Zoom Premium akan naik sebesar 0,389. Berdasarkan data demografi responden, ulasan ataupun testimoni ini diperkirakan sering calon pelanggan Zoom Premium dapatkan dari media sosial Instagram. Mereka yang telah berlangganan aplikasi Zoom Premium dapat mengabadikan momennya menggunakan aplikasi tersebut dan membagikannya ke story maupun feed Instagram untuk mengundang calon pelanggan bertanya testimoni dari pengguna tersebut. Dengan demikian, apabila merujuk akan teori network externalities, teori ini dapat menjelaskan alasan getok tular elektronik memiliki kontribusi yang lebih kuat, yaitu karena situasi di sekitar pada saat ini menuntut, menginspirasi, dan/atau menggetok banyak orang untuk turut menggunakan Zoom Premium.

Lagipula, para responden juga mengakui bahwa banyak orang secara online membicarakan aplikasi Zoom Premium $(M: 5,18)$. Pengakuan ini secara sederhana juga memberikan sebuah pelajaran yang dapat dipetik untuk Zoom. Betul bahwa getok tular merupakan medium pemasaran tertua, tetapi kontribusinya tetap paling kuat hingga saat ini (Kimmel \& Kitchen, 2014). Peluang menunjukkan bahwa sedang banyak orang yang secara daring membicarakan aplikasi ini, maka akan semakin bagus apabila pembicaraan daring ini semakin banyak dan tetap dijaga. Kotler (2017, p. 190) menjelaskan bahwa calon konsumen mencari informasi terkait produk bisa secara personal (teman, 
pelanggan lain, keluarga, dsb.), maupun secara komersial. Secara personal, Zoom dapat meminta kesediaan penggunanya untuk membagikan ulasan ke media sosial. Misal, ketika pengguna tersebut membagikan ulasan ke Instagram dan melakukan tag kepada lima pengguna Instagram lain, pengguna tersebut mendapatkan potongan $10 \%$ biaya berlangganan bulan selanjutnya. Secara komersial, pemasaran getok tular elektronik yang dapat digunakan Zoom Premium adalah influencer marketing. Zoom Premium dapat menyewa jasa influencer untuk mempromosikan pentingnya menggunakan Zoom Premium lewat media sosialnya. Dua teknik ini setidaknya akan menguatkan keyakinan semakin banyak orang untuk mau berlangganan Zoom Premium.

\section{Kesimpulan}

Pandemi COVID-19 menyebabkan banyak aktivitas berlangsung secara daring, salah satunya adalah kegiatan konferensi. Berbagai pilihan aplikasi konferensi video pun bermunculan dan masyarakat menjadi selektif untuk menggunakan mana yang sesuai dengan kebutuhannya. Pengetahuan produk dan getok tular elektronik adalah dua hal yang setidaknya berkontribusi dalam keputusan pembelian. Hasil penelitian ini membuktikan bahwa pengetahuan produk dan getok tular elektronik membawa pengaruh pada keputusan berlangganan aplikasi konferensi video Zoom Premium. Besar pengaruh yang ditimbulkan adalah sebesar 43,4\%.

Jumlah pengguna Zoom Premium di Indonesia bersifat fluktuatif. Ini mengindikasikan tidak adanya jumlah yang mutlak dan menjadi keterbatasan dari penelitian ini. Maka dari itu, pengumpulan data hanya dibatasi atas jumlah sampel yang berhasil dihimpun oleh peneliti. Besar $43,4 \%$ ini berlaku pada penggunaan aplikasi konferensi video Zoom Premium saja. Oleh karena itu, para peneliti selanjutnya diharapkan dapat meneliti aplikasi konferensi video lainnya. Para peneliti selanjutnya seyogianya dapat mencari tahu sisa 56,6\% yang dapat memengaruhi keputusan berlangganan aplikasi Zoom Premium. Gaya hidup konsumen dapat menjadi salah satu variabel independen yang menarik untuk ditelaah pada penelitian selanjutnya. Para peneliti selanjutnya juga dapat menelaah pada objek berupa layanan subscription lain.

\section{Referensi}

123ish. (2019). Informasi lengkap Skype! Milenial wajib tahu. 123ish. https://www.123ish.com/id/entries/1892-informasi-lengkap-skype--milenialwajib-tahu

Akbar, M. J. C., \& Sunarti. (2018). Pengaruh electronic word of mouth terhadap keputusan pembelian (survei pada konsumen restoran Sushi Tei Kelapa Gading). Jurnal Administrasi Bisnis (JAB), Vol. 60(No. 3), 45-51. http://administrasibisnis.studentjournal.ub.ac.id/index.php/jab/article/view/253 $1 / 2922$

Annisa, I. T., \& Wijaya, A. P. (2019). Pengaruh keterlibatan dan pengetahuan produk terhadap keputusan pembelian jamu masuk angin kemasan. Jurnal Ilmiah Manajemen, 14(2), 122-137. https://doi.org/10.33369/insight.14.2.122-137

Annur, C. M. (2020). Pengguna video melonjak selama pandemi, pendapatan Zoom naik 169\%. Katadata. https://katadata.co.id/ekarina/digital/5ed8a03baa91b/penggunavideo-melonjak-selama-pandemi-pendapatan-zoom-naik-169

Baltrusaitis, J. (2020). Zoom downloads increase 1,270\% from employers working from home. LearnBonds. https://learnbonds.com/news/zoom-downloads-increase1270-from-employers-working-from-home/

Bryman, A. (2012). Social research methods (4th ed.). Oxford University Press.

Databoks. (2020). Zoom, aplikasi bisnis paling banyak diunduh 2020. Databoks. 
https://databoks.katadata.co.id/datapublish/2021/01/29/zoom-aplikasi-bisnispaling-banyak-diunduh-2020

Dattalo, P. (2018). Determining sample size using fast and slow thinking. Journal of Social Service Research, 44(2), 180-190. https://doi.org/10.1080/01488376.2018.1436632

Evgeniy, Y., Lee, K., \& Roh, T. (2019). The effect of eWOM on purchase intention for Korean-brand cars in Russia: The mediating role of brand image and perceived quality. Journal of Korea Trade, 23(5), 102-117. https://doi.org/10.35611/jkt.2019.23.5.102

Fauziyah, S. R. (2014). Peran tokoh agama dalam masyarakat modern menurut Anthony Giddens. Universitas Islam Negeri Sunan Kalijaga.

Guastella, G. (2017). Word of mouth. Oxford University Press.

Ismagilova, E., Dwivedi, Y. K., Slade, E., \& Williams, M. D. (2017). Electronic word of mouth (eWOM) in the marketing context. Springer.

Khalin, V., \& Chernova, G. (2018). Digitalization and its impact on the Russian economy and society: Advantages, challenges, threats and risks. Administrative Consulting, 10, 46-63. https://doi.org/10.22394/1726-1139-2018-10-46-63

Kimmel, A. J., \& Kitchen, P. J. (2014). WOM and social media: Presaging future directions for research and practice. Journal of Marketing Communications, 20(1-2), 5-20. https://doi.org/10.1080/13527266.2013.797730

Kotler, P., \& Armstrong, G. (2015). Principles of marketing (16th ed.). Pearson Education Limited.

Kotler, P., Keller, K., Ang, S., Tan, C., \& Leong, S. (2017). Marketing management: An Asian perspective (7th ed.). Pearson Education Limited.

Kotler, P., \& Keller, K. L. (2013). Manajemen pemasaran (13th ed.). Erlangga.

Martin, K. D., \& Murphy, P. E. (2017). The role of data privacy in marketing. Journal of the Academy of Marketing Science, 45(2), 135-155. https://doi.org/10.1007/s11747016-0495-4

Maulana, F. R., Hasnita, N., \& Evriyenni, E. (2020). Pengaruh pengetahuan produk dan word of mouth terhadap keputusan nasabah memilih bank syariah. JIHBIZ: Global Journal of Islamic Banking and Finance, 2(2), 124-137. https://doi.org/10.22373/jihbiz.v2i2.8644

Mubtadi, V. (2011). Kedubes RI pererat persahabatan AS-Indonesia via "Skype Friends." VOA Indonesia. https://www.voaindonesia.com/a/kedubes-as-pereratpersahabatan-as-indonesia-via-skype-friends-119263109/91773.html

Nepomuceno, M. V., Laroche, M., \& Richard, M. O. (2014). How to reduce perceived risk when buying online: The interactions between intangibility, product knowledge, brand familiarity, privacy and security concerns. Journal of Retailing and Consumer Services, 21(4), 619-629. https://doi.org/10.1016/j.jretconser.2013.11.006

Neuman, W. L. (2014). Social research methods: Qualitative and quantitative approaches (7th ed.). Pearson Education Limited.

Pertiwi, W. K. (2020). Jumlah pengguna Zoom terus naik meskipun ada isu keamanan. Tekno Kompas. https://tekno.kompas.com/read/2020/04/25/17160067/jumlahpengguna-zoom-terus-naik-meskipun-ada-isu-keamanan

Peter, J. P., \& Olson, J. C. (2013). Perilaku konsumen \& strategi pemasaran (9th ed.). Salemba Empat.

Populix. (2020). Aplikasi video conference saat pandemi, apa yang berubah? Populix. https://www.info.populix.co/post/aplikasi-video-conference-saat-pandemi-apayang-berubah 
Purnama, P., Anggraini, R., Hartono, A., Irwansyah, \& Ernungtyas, N. F. (2019). Terpaan iklan digital, word of mouth dan komunikasi pemasaran interaktif pada keputusan pembelian produk perawatan tubuh. KOMUNIDA: Media Komunikasi Dan Dakwah, 9(2), 192-209. https://doi.org/10.35905/komunida.v9i2.1123

Rajaguguk, A., Effendi, M., \& Suryani, A. (2021). Pengaruh pengetahuan produk dan kualitas pelayanan terhadap keputusan pembelian konsumen Homesmart Rantau Prapat (studi kasus saat pandemi covid-19). Warta Dharmawangsa, 15(2), 292-298. https://doi.org/10.46576/wdw.v15i2.1220

Rupayana, I. K., Suartina, I. W., \& Mashyuni, I. (2021). Pengaruh kualitas produk, impulse buying dan electronic word of mouth (ewom) terhadap keputusan pembelian pada produk smartphone merek OPPO di kota Denpasar. Jurnal Widya Amrita, 1(1), 233247. https://doi.org/10.32795/widyaamrita.v1i1.1167

Rusniati, \& Rahmawati, R. (2019). Green product: Pengaruh pengetahuan produk, pengetahuan pembelian dan pengetahuan pemakaian terhadap keputusan $\begin{array}{lll}\text { pembelian. } & \text { INTEKNA, 60-68. }\end{array}$ https://ejurnal.poliban.ac.id/index.php/intekna/article/view/727/631

Salsabila, S. (2013). ITB manfaatkan teknologi video conference dalam dunia pendidikan. Itb.Ac.Id. https://www.itb.ac.id/berita/detail/4040/itb-manfaatkan-teknologivideo-conference-dalam-dunia-pendidikan

Sari, N., Saputra, M., \& Husein, J. (2017). Pengaruh electronic word of mouth terhadap keputusan pembelian pada toko online bukalapak.com. Jurnal Manajemen Magister, 3(1), 96-106. https://jurnal.darmajaya.ac.id/index.php/jmmd/article/view/968

Sindunata, I., \& Wahyudi, B. A. (2018). Pengaruh electronic word of mouth terhadap keputusan pembelian di agoda.com. Hospitality Dan Manajemen Jasa, 6(1), 128-138. https://jurnal.darmajaya.ac.id/index.php/jmmd/article/view/968

Sitompul, S. (2021). Pengaruh pengetahuan label dan kesadaran merek terhadap keputusan pembelian kosmetik melalui rekomendasi kelompok sebagai variabel mederator. Jurnal Kajian Ekonomi Hukum Syariah, 7(1), 50-64. http://journal.iaisambas.ac.id/index.php/Shar-e/article/view/402/396

Sriyanto, A., \& Kuncoro, A. W. (2019). Pengaruh brand ambassador, minat beli dan testimoni terhadap keputusan pembelian. Jurnal Ekonomika Dan Manajemen, 8(1), 21-34. https://journal.budiluhur.ac.id/index.php/ema/article/view/858/660

Sudarita, Y. M. I. M. (2020). Pengaruh e-wom terhadap keputusan pembelian produk kosmetik (survey followers aktif akun @jelitacosmetic_). Commercium, 3(1), 36-40. https://jurnalmahasiswa.unesa.ac.id/index.php/Commercium/article/view/34875

Sudarsono, A. B., \& Olivia, H. (2021). Mediamorfosis industri media televisi: Studi lembaga bisnis EMTEK pada platform digital vidio.com. COMMENTATE: Journal of Communication Management, 2(1), 1-16. http://journal.lspr.edu/index.php/commentate/article/view/221

Tumengkol, A. (2020). Lebaran tahun ini jadi ajang "The New Normal." Waspada Online. https://waspada.co.id/2020/05/lebaran-tahun-ini-jadi-ajang-the-new-normal/

Utama, R. D. H., \& Rosalina, F. (2016). Pengaruh testimoni dalam periklanan (the influence of testimony in advertising). Jurnal Manajerial, 15(1), 97-117. https://ejournal.upi.edu/index.php/manajerial/article/view/9475/5864

Wei, P. S., \& Lu, H. P. (2014). Why do people play mobile social games? An examination of network externalities and of uses and gratifications. Internet Research, 24(3), 313331. https://doi.org/10.1108/IntR-04-2013-0082

Weitzl, W. (2017). Measuring electronic word-of-mouth effectiveness: Developing and applying the eWOM trust scale. Gabler Verlag.

West, R., \& Turner, L. H. (2019). Introducing communication theory: Analysis and 
114 Expose: Jurnal Ilmu Komunikasi, Vol. 4(2), November 2021

application (6th ed.). McGraw-Hill Education.

Worldometer. (2021). Report coronavirus cases. Worldometer. https://www.worldometers.info/coronavirus/ 